\title{
Childhood and Scientific Literacy: Contributions of History and Epistemology
}

\author{
Aldo Sena de Oliveira1,2, Vanessa Lima Bertolazi Simon², Alexandre Simon² \\ ${ }^{1}$ Department of Exact Sciences and Education, Blumenau Center, Federal University of Santa Catarina, Blumenau, Brazil \\ ${ }^{2}$ University of Blumenau, Blumenau, Brazil \\ Email: aldo.sena@ufsc.br
}

How to cite this paper: de Oliveira, A.S., Simon, V.L.B. and Simon, A. (2018) Childhood and Scientific Literacy: Contributions of History and Epistemology. Open Journal of Social Sciences, 6, 216-225. https://doi.org/10.4236/jss.2018.68017

Received: July 22, 2108

Accepted: August 21, 2018

Published: August 24, 2018

Copyright (C) 2018 by authors and Scientific Research Publishing Inc. This work is licensed under the Creative Commons Attribution International License (CC BY 4.0).

http://creativecommons.org/licenses/by/4.0/

\begin{abstract}
In this article we present some narratives about childhood from the perspective of history and epistemology. The theme will be interwoven with the discourses that permeate multiple debates that are present in the context of contemporary education, especially from the point of view of scientific literacy. The intention is not to exhaust the theme, given its complexity, but to present some guiding axes from the dialogue where we allow ourselves to understand childhood beyond its ontological meaning and allow us to understand the child as a socio-historical and cultural subject.
\end{abstract}

\section{Keywords}

Childhood, Scientific Literacy, Epistemology

\section{Introduction}

The understanding of childhood from elements that deal with its historical and social context has reached important dialogues in the most diverse social sectors, being often embedded in political, economic and educational discourses [1]. Childhood has been conceived as a typical discovery of modernity, whose genesis is strongly related to the development of schooling, the influence of Christianity and new forms of family life [2]. The studies of [2] reaffirm the conception of childhood as something that is being built, created from new ways of speaking and feeling of adults [3] to the detriment of a notion of childhood as a natural stage of human development.

The invented childhood image is constituted from cultural practices, typical of a historical context. Conceiving the child as a miniature adult was a common practice until the seventeenth century, when it was considered that there were no 
significant differences between adult and infant rationale, feelings and actions [1]. When analyzing the history of childhood, there is an almost generalized absence in antiquity and in the Middle Ages, since the device of infantility did not operate to specifically create the "infantile", although it already machine, which had been operationally operating [4].

Etymologically the word childhood, comes from the verb fari which means to speak; infans, antis (who does not speak, who is young, childish, child). Infantile terminology leads to the understanding of childhood as a period characterized by difficulty or inability to speak [5].

In addition to this perspective, the child learns to speak when it develops during a social group, because it is through living with more experienced people that articulated speech becomes possible. It is important to emphasize that this development of speech will depend on the structure and position in which the child is in the group. The use of language in turn will help to strengthen the bonds between adults and children, expanding their communication and development within the group in which it is inserted [6].

In this way, it is through language that the child constructs the representation of the reality in which it is inserted [7]. The language of the child can, therefore, be transformed according to his conduct in the environment in which he lives. For the author it is using language, through the re-creation of its historical context in which its participation occurs in the dialectic of subordination and begins to reconquer a place of subject.

In the history of science, recently, childhood-articulated according to cultural and biological perspectives-has come to be recognized as a special era of development, in which the subject needs care, protection and supervision [1].

Children today grow in a culturally diverse, socially complex and technically highly developed world. The point of reference for discussion and socio-pedagogical view of childhood was the work of Aries "Centuries of Childhood" published in 1962, dealing with childhood from a historical perspective and figurative art. In recent times (more than the last hundred years) a child is observed in the context of a discourse and turns away from being treated as "the little person" [8]. In repeating the major social, cultural, and economic factors that defined the recognizable discourse in childhood [9] describes an interest in childhood in the early 17th century, when an initial debate about the child's position and nature was initiated. It starts with Locke's empiricism and goes on to the romantic image of Rousseau's childhood as an idyllic time full of joy, protection, independence and dependency. The industrial period places a child in the world of work a little early, but at the same time opens some new areas of interest the child and childhood-children's rights, concern for children's health and development.

A little later, due to intensive research in the field of developmental psychology, a child is placed within the existing developmental stages, which are characterized by specific thinking, communication and influence of a child's environment. Patterns in the function of setting "normal" levels in children with respect 
to dominant developmental criteria disappear.

In this article, we briefly report some contributions from history and epistemology to understanding childhood and its relationships with scientific and technological literacy. The research carried out is of qualitative character, constructed from bibliographical researches in indexed periodicals.

\section{Research on Childhood: A Short Cut}

The research with the "small children", imposes itself as a condition of complexity, due to a difficulty, in many cases, to understand children's language. Understanding childhood and thinking pedagogical perspectives for its learning goes through the analysis of a historical, social and cultural context, making it necessary to address the genesis of the educational organization in which the child is inserted.

Many researches about child development are based on the description and understanding of children from their own context, through the observation of their behavior in the face of different situations that affect their reality [10].

Since the 1990s, experts from different areas of knowledge have dealt with issues directly related to childhood, and through this perspective, important methodological contributions have been achieved [10]. Such research makes it possible to look at children in different ways and seek to interpret what is spoken by them, identifying new sources, objects and methodological tools. To bring the childhood/child, as well as their voices and actions, as an object and methodologically, that is, to talk with children, is to consider the ways of seeing, thinking and feeling that are their own [10].

Through the performance and observation of activities it is possible to explore the physical world of the child, whose activities in turn would respond to the anxieties about child learning and the search for different practices and methodologies for application in the context educational and pedagogical [1]. The choice by observing activities of exploration of the physical world has also its origin in the trajectory of the own infantile education, whose history presents/displays a course not linear. The central concern is organized around issues such as: what knowledge to socialize? What are the interests of children in this age group? What are they capable of learning? How to organize the activities? History has shown us that these inquiries have undergone changes over the years in a dialogue that covers social and political issues, as well as educational ones [11].

\section{The History and Epistemology of Childhood: Brief Notes}

In Brazil, the children lived according to their peers, whose affection was given to them until they were seven years old, regardless of the condition and social hierarchy. From this age the children of slaves began to work with their parents in the field. On September 28, 1871, the Law of Free Womb was signed, giving freedom to children born after this date. However, the guardianship of the freedmen was under the responsibility of the owners of their mothers and thus 
they would be educated until the eight years of age. The children who did not receive this care, ended up being abandoned and would be educated by associations created for this purpose [5].

The constitution of public education from 1820 and 1830, through political and cultural leaderships, organized institutions had the objective of guarding, protecting and training the population. At first these institutions came to attend to their children, by means of French classes, library use and higher courses, while the rest of the population was provided with asylums, houses of correction and mercy. One observes the political interest in having control over the poor children, to coerce them to work and to behave in a way to receive punishments or awards according to their conduct [10].

In 1873, after the closure of the institutions that housed these children, these were sent to the Navy Arsenal, which became known as the School of Learners of Mariners. On March 25, 1824, the Constitution of the Empire was enacted, which granted free primary education to all citizens, although it became effective only in 1827 [10].

The lack of schools and resources did not allow innovations, besides the already used system called "pombalino", name given about Marquês de Pombal, Portuguese Prime Minister Sebastião José de Carvalho e Melo [5].

In 1933, the National Conference for the Protection of Children in Rio de Janeiro, in which Anísio Teixeira, defended that the preschool child should be seen under the pedagogical, mental, social and mentioned the importance of toys, creating a relationship with or play. With the regulation of women's work in 1932, industries and commerce that had more than 30 women working, should have a place, a kindergarten for children's education, that would meet the needs of working mothers and while of children [5].

Under Act 4.024/61, children under the age of seven should receive either a mother's education or kindergarten. In the 1960s, the Department of the Child released a plan for assistance to preschool, increasing the creation of schools and kindergartens [9]. At the end of the 1980s, several claims in defense of early childhood education began to be observed, as in 1988 Art. 208, guarantees education from zero to six years of age in kindergartens and pre-school as a citizen's right and state duty is emphasized. Art. 211 emphasizes the municipalization of early childhood education and inclusion of day care centers in the educational system [5]-[10].

In the sixteenth and seventeenth centuries in Europe, great changes took place, among them the scientific development and the invention of the press. The latter, of great importance in allowing access to information more quickly, enabling the reading of the Bible. In this way, there was a concern of the religious entities so that their faithful had the minimum of learning and could have access to the sacred book [12].

Revolutions and the birth of the school for children from the age of six, were also part of the sixteenth and seventeenth centuries [12] [13]. From this period, 
important contributions in the teaching and pedagogical methodology were made necessary, due to the creation of educational institutions and kindergartens.

In 1628 the pedagogue Theco Comenius, founder of modern Didactics, published a book entitled "The School Infancy", which talked about the education of "little children" and added that they learn through the senses, experience and direct contact with objects, this learning would be internalized and, in the future, interpreted by reason. In his work he sought to constitute a global philosophical system called "Pansofia", which sought to introduce philosophy for universal use, something beyond his time, in this period [14].

In the seventeenth century, metaphysics could explain several questions about child development as well as the interactions between man and nature.

The central idea is undoubtedly the formative nature which, when reflected in the human spirit thanks to the parallelism between man and nature, provokes, through the same natural order, the educational process. It is the order of things which constitutes the true educating principle, but it is an active order, and the educator can fulfill his role only if he remains an instrument in the hands of nature. Education, then, is incorporated into the forming process that animates all beings, being only one aspect of this vast development [14].

The author mentioned above, defended the pedagogy of spontaneous development, emphasizing that practical learning overlaps with theories. In his work it is possible to observe the defense in the performance of activities through the interest, which are not empty or an imposition by the action. Students need to be seduced through information, through what can be easily understood and useful to them, so according to the author, would be with the attention always available [14].

Modern schools, designed for education, organized spaces with defined schedules, with professionals and environments qualified to serve small children. Even though these schools are different, we do not want, however, to teach different things, but the same things differently. I mean, all the things that can make men, real men, scientists, real scientists. The education will be according to the age and the previous level of preparation that should lead gradually and increasingly to growth [14].

The first kindergarten was founded in 1840 by Fröebel, an author who contributed heavily to the creation of kindergartens, as well as a methodology used to this day [9]. His conception of kindergarten promotes sentimental "discussions" today about his methodologies and pedagogical proposals, which used games and gifts. This material, developed by Fröbel and associated with that of Mantessori, is currently considered the most suitable and perspicacious program for children between 3 and 6 years of age [15].

Fröebel attributes an analogy to kindergarten, in which adults and teachers should be gardeners and the children the plants to be cared for. At first its appearance, it came to please and serve the rich families, which could put their children in the intention of the continuity of the learning in the later ages [12] 
[13]. According to Fröebel, children should learn through diversified activities and materials, thus ensuring abstract learning. For the author, school institutions are influenced according to the historical, political, social and economic context in which they are inserted. That is, the work developed in early childhood education is shaped according to the historical representations that deal with this level of education [12].

From the eighteenth century there was a need to educate, without there being "physical punishment". In this way, scholars of the time agreed that children should be disciplined early on. Rosseau, through one of his works entitled Emilio, considered the "true bible of the pedagogies of freedom" [16], emphasizes the importance of the child in his fullness of age, emphasizing that the child up to 12 years old would be in the process of the development of reason and that until then would be composed of senses, emotions and physical body [12].

Thus, it is necessary for the school to submit to pedagogical work, searching for practices and methodologies in effect, to not only transmit to future generations, the responsibilities that our current society demands. In this sense, the search for teaching autonomy to students through teaching administered in school institutions is evident [16].

The school in turn must use the possibilities, skills and abilities of the students, valuing their context and their experiences. Understanding that education is one of the aspects of nature-forming mechanisms, and thus integrating the educational process into a system that is the fundamental axis of the whole teaching process [16]. Thus, it reaffirms that the educational process is not linked to the school or the family and that the development of the being takes place throughout its life in society

\section{Childhood, School and Science: Notes on Scientific and Technological Literacy}

We present a brief reflection in addition to the questions surrounding the historical and epistemological assumptions that guide practices in childhood, but which are inserted in the context of children's learning, especially that which appropriates science through the pillars of scientific and technological literacy. Once again, we emphasize that it is not the intention of the authors to present a thorough review on this subject, which would allow many bibliographical productions, but highlight the contributions of literacy in the context of contemporary school.

Scientific and technical literacy is in vogue and has been discussed for some time in Anglo-Saxon countries and in northern European countries [17]. For the author, the term scientific literacy denotes a type of knowledge, capacity or knowledge and know-how that, in our technical-scientific world, would be a counterpart to what was literacy in the last century.

The OECD PISA Framework (2015) defines scientific literacy as "the ability to engage with science-related issues, and with the ideas of science, as a reflective 
citizen". A scientifically literate person, therefore, is willing to engage in reasoned discourse about science and technology which requires the competencies to explain phenomena scientifically-recognize, offer and evaluate explanations for a range of natural and technological phenomena; evaluate and design scientific inquiry - describe and appraise scientific investigations and propose ways of addressing questions scientifically; interpret data and evidence scientifically - analyze and evaluate data, claims and arguments in a variety of representations and draw appropriate scientific conclusions [18].

Scientific and technological literacy in Brazil is an instrument that emerges from the context of globalization "understood as what a specific public-the school public-should know about science, technology and society based on knowledge acquired in diverse contexts (school, museum, magazine, etc.); public attitudes about science and technology and information obtained through means of scientific and technological dissemination" [19].

In fact, the term Scientific and Technological Literacy (STL) itself has a range of meanings. This is due to geographical, cultural and historical issues, which are translated through expressions in the quest for the democratization of sciences and aim to facilitate public knowledge [20].

Gerard Fourez describes the importance of Scientific and Technological Literacy (STL) to the present day, making a comparison of how important the process of literacy and literacy in the late nineteenth century was, arguing that it is through these prerogatives that cause the insertion of citizens in society. Stressing that through the STL an individual can organize his/her thinking in a rational way, seeking to build a critical awareness in the different daily situations in which we live [20].

Scientific thinking and new technologies are needed to solve the problems of the 21 st century. Scientific and technological literacy is closely linked to the social and cultural contexts of society [17]. The perspective of scientific literacy can be expressed from certain terms with specific objectives, being humanistic, social and economic [21].

- Humanistic goals constitute the way in which it is possible to situate itself in a technical-scientific society and the way in which the sciences can be decoded, to allow the critical autonomy and cultural participation in our reality.

- The social objectives aim to reduce the inequalities in our society, contemplating the active and critical participation of the people on the technic$\mathrm{al} /$ scientific issues.

- The economic objectives seek to encourage the promotion of technological and economic potential, aiming at the production and increase of wealth in our industrialized society.

It is necessary to develop a new type of knowledge or an updated curriculum structure, reinforcing that the curriculum of the schools does not become a cluster of subjects. On the contrary, through Scientific and Technical Literacy, this restructuring could guarantee an intellectual development to the student in the 
different areas of knowledge in an interdisciplinary way [17].

Due to the lack of relation between the content transmitted and the daily life, the student ends up being discouraged, focusing on the decrease of dedication to teaching. Emphasizing that for the student to gain interest in scientific knowledge, it must serve to interpret and resolve the situations of their reality, giving meaning to their life [22].

Three understandings that complement each other in the definition of scientific literacy and that justify the importance of thinking it also for the child [23].

1) Scientific literacy as a process that takes place in and out of school, from the beginning of the child's insertion in the world, full of science and technology productions.

2) STL as a formative objective, which aims at the appropriation of elements of science to understand the social context and participate actively and critically in decision-making processes.

3) STL as the right of all: the right to education, culture, knowledge, understanding of the reality in which we are inserted, to the construction of new world readings.

In a bibliographical production with great volume of citations in later researches, present a discussion about STL in the context of the initial series, understanding it as lifelong activity, being systematized in the school space, but transcending its dimensions to non-formal educational spaces permeated by different media and languages. For the authors, it is possible to develop scientific literacy in the initial years of elementary education (which, at the time of publication of the article, served children from 7 to 10 years), regardless of the field of alphabetic writing [23]. The authors' contribution contrasts with the idea that STL depends on the prior appropriation of alphabetic writing, which would exclude from this process children who do not master the code. They argue that STL should be understood as the process by which the language of the natural sciences acquires meanings, constituting a means for the individual to broaden his knowledge universe, his culture, as a citizen inserted in society [24].

Knowing science is something that should cross the boundaries of schooling, to provide children with a basis for scientific training in order to enable the development of more conscious citizens about the use of natural resources, with access to technologies that contribute to an improvement of life for society.

In this context, STL can be understood as an out-of-school course that involves: a) the promotion of dialogues and approximations between the experiential culture of individuals and the scientific culture; b) the appropriation of knowledge related to scientific terms and concepts, the nature of science, the relations between science, technology and society; $c$ ) the promotion of the necessary conditions for critical reading of reality, participation in public debate, social intervention in an emancipatory and social inclusion perspective [25].

The STL must be a promoter of the construction of knowledge, what Freire calls epistemological consciousness, and favor social participation. In this sense, 
actions aimed at the STL must be permeated by an emancipatory project and social inclusion, from a perspective of human defense, social justice and democracy.

\section{Final Considerations}

Epistemology and history are of great relevance for the child's understanding of a historical-cultural agent. Understanding how the concept of childhood was constructed, in accordance with epistemological assumptions, enables the understanding of the child as a socially active subject. In this sense, the importance of promoting multiple dialogues and intersections between children's culture and scientific culture is highlighted. In an objective way, school practices need to be elaborated and developed considering the issues of science. In this way, children should have contact with nature sciences and their technologies since entering formal education.

New studies involving scientific literacy for children are needed and signal a fragility of this research, which will be expanded and disseminated in the future.

Thus, there is also a new context of learning, which must be considered in the elaboration of pedagogical practices, to make children more critical and active in contemporary society. This action, in turn, must be inspired by educational institutions and teaching professionals, who can promote scientific and technological literacy, with the intention of building skills and competences that help children to experience different social and cultural contexts, with a view to a learning and schooling appropriate to contemporaneity.

\section{Conflicts of Interest}

The authors declare no conflicts of interest regarding the publication of this paper.

\section{References}

[1] Oliveira, A.S., Brondani, P.B. and Meier, L. (2017) The Chemistry, the Imaginary and the Children: Notes on the Postmodern Curriculum. InterEspaço, Grajaú, 57-69.

[2] Ariès, P. (1981) Child and Family's Social History. 2nd Edition, Zahar Editores, Rio de Janeiro.

[3] Ghiraldelli Jr., P. (2000) Childhood Conceptions and Modern and Contemporary Educational Theories. Educação e Realidade, Porto Alegre, 45-58.

[4] Corazza, S.M. (2002) Childhood \& Education: Once Upon a Time... Do You Want Me to Tell You Again? Vozes, Petrópolis.

[5] Ferreira, E.M. (2012) "You Look like a Child!", the Spaces of Participation of Children in Educational Practices. Master Dissertation, Universidade Federal da Grande Dourados, Dourados.

[6] Elias, N. (1994) The Society of Individuals. Jorge Zahar, Rio de Janeiro.

[7] Souza, S.J. (1994) Childhood and Language: Backtin, Vygotsky e Benjamin. Papirus, Campinas. 
[8] Sagud, M. (2015) Contemporary Childhood and the Institutional Context. Croatian Journal of Education, 17, 265-274.

[9] Kellet, M. (2010) Rethinking Children and Research, Attitudes in Contemporary Society. Continuum International Publishing Group, London.

[10] Ferreira, E.M. and Sarat, M. (2013) Child(ren) and Childhood(s): Perspectives on the History of Education. Revista Linhas, Florianópolis, 234-252.

[11] Goulart, M.I.M. (2007) Learning by Participating: The Exploration of the Physical World by the Child. 30 a Meeting of ANPED, Education of Children from 0 to 6 Years Old, Caxambu, 7-10 October 2007, 3404.

[12] Riscaroli, E. (2017) Epistemologies of Childhood. 1st Edition, Appris, Curitiba.

[13] Arce, A. (2002) Lina, an Exemplary Child! Friedrich Froebel and the Pedagogy of Kindergartens. Revista Brasileira de Educação.

http://www.scielo.br/scielo.php?script=sci_arttext\&pid=S1413-24782002000200009 \&lang $=\mathrm{pt}$

[14] Piaget, J. (2010) Jan Amos Comênio. Fundação Joaquim Nabuco, Recife.

[15] Heiland, H. (2010) Friedrich Fröbel. Fundação Joaquim Nabuco, Recife.

[16] Soëtard, M. (2010) Jean-Jacques Rousseau. Fundação Joaquim Nabuco, Recife.

[17] Fourez, G. (2005) Scientific and Technological Literacy: About the Aims of Science Education. Colihue, Buenos Aires.

[18] Leal, M.C. and Souza, G.G. (1997) Myth, Science and Technology in Science Teaching: The Time of the School and the Museum. Atlas of the 1 st National Meeting of Research in Science Teaching, Águas de Lindóia, 27-29.

[19] Sasseron, L.H. and Carvalho, A.M.P. (2011) Scientific Literacy: A Bibliographical Review. Investigações em Ensino de Ciências, 16, 59-77.

[20] Fourez, G. (2003) Crisis in Science Teaching? Investigações em Ensino de Ciências, 8, 109-123.

[21] Nehring, C.M., Silva, C.S., Trindade, J.A.O., Pietrocola, M., Leite, C.M.L. and Pinheiro, T.F. (2000) The Islands of Rationality and Meaningful Knowledge: The Teaching of Science through Projects. Ensaio Pesquisa em Educação em Ciências, 2, 88-105.

[22] Marques, A.C.T.L. and Marandino, M. (2018) Scientific Literacy, Children and Spaces Non-Formal Education: Possible Dialogues. Educação e Pesquisa, 44, e170831.

[23] Lorenzetti, L. and Delizoicov, D. (2001) Scientific Literacy in the Context of the Initial Grades. Ensaio Pesquisa em Educação em Ciências, 3, 45-61.

[24] Marques, A.C.T.L., Scalfi, G., Iszlaji, C., Milan, B. and Marandino, M. (2017) Scientific and Child Literacy: A Proposal of a Theoretical-Methodological Tool to Analyze Educational Actions in Non-Formal Education Spaces. Anais do XI ENPEC, Florianópolis.

[25] Chassot, A. (2014) Scientific Literacy: Issues and Challenges for Education. 6th Edition, Editora Unijuí, Ijuí. 